\title{
O ensino da História, a formação de professores e a Pós-Graduação
}

Marieta Ferreira*

Resumo: O objetivo deste artigo é apresentar algumas reflexões sobre os desafios para a formação dos professores da educação básica tendo como eixo o ensino de história. A ideia básica é acompanhar os diferentes momentos desse percurso, que se inicia com as primeiras licenciaturas nos anos trinta; as transformações profundas trazidas pelo regime militar, com a Reforma Universitária a e a expansão das pós-graduações; e finalmente a emergência dos mestrados profissionais, em especial o ProfHistória.

Palavras-chave: Ensino de história. Formação de professores. Mestrados profissionais.

\section{Introdução}

Em um momento que a discussão sobre os problemas da educação básica brasileira estão na ordem do dia e a mídia, as organizações ligadas ao ensino público ou privado, os profissionais da área debatem a reformulação do ensino médio e a criação de uma Base Nacional Curricular, nada mais oportuno do que rever ao caminhos percorridos no processo de formação de professores, elemento chave, para o sucesso de qualquer política pública que busque qualidade no país.

* Marieta de Moraes Ferreira é doutora em História, professora titular do Instituto de História da UFRJ, coordenadora nacional do ProfHistória, pesquisadora da FGV. E-mail: marieta@fgv.br

Anos 90, Porto Alegre, v. 23, n. 44, p. 21-49, dez. 2016 


\section{Primeiros tempos (1938-1964): o foco nas licenciaturas}

A criação dos cursos universitários de História e Geografia, na década de 1930, teve como objetivo principal a formação de professores para a educação básica. Em São Paulo a Faculdade de Filosofia Ciências e Letras, criada em 1934, desde suas origens dedicou-se a formar seus alunos para atuar como docentes. Igualmente no Rio de Janeiro, tanto a Universidade do Distrito Federal, que teve vida curta, como a Faculdade Nacional de Filosofia da Universidade do Brasil (FNFi-UB) caminharam na mesma direção. Criada em 1939, a FNFi visava à consolidação de uma universidade-padrão que servisse de modelo para as outras que viessem a se constituir, e tinha como objetivo prioritário preparar candidatos ao magistério do ensino secundário e normal (FERREIRA, 2013).

A FNFi foi organizada em quatro seções fundamentais: de Filosofia, de Ciências, de Letras e de Pedagogia. Haveria, ainda, uma seção especial de Didática, História e Geografia, que até 1955 constituíram um único curso, ligavam-se à Seção de Ciências. Fundada durante a ditadura do Estado Novo e marcada por ideias autoritárias, a FNFi foi também fortemente influenciada por setores católicos. Destinado a desempenhar um papel-chave na formação dos futuros professores secundários, seu curso de História e Geografia tinha assim o compromisso de reforçar os laços da identidade brasileira por meio da ênfase na unidade nacional e no papel dos grandes heróis como construtores da Nação (FERREIRA, 2013).

O fim do Estado Novo em 1945 abriu espaço para algumas transformações no cenário educacional brasileiro. A Igreja e os setores mais conservadores temiam que o desenvolvimento do ensino superior trouxesse ao país valores ligados ao liberalismo e ao materialismo e, para barrar tal possibilidade, se articularam em defesa de um projeto de ensino universitário subordinado à hierarquia eclesiástica. Foi assim aprovada, em 1946, a primeira instituição com o título de Pontifícia Universidade Católica (PUC) em São Paulo, no campo protestante surgiram instituições, como a Universidade Presbiteriana Mackenzie, também em São Paulo (MUGUET, 2016).

A década de 1950 aprofundou ainda mais esse processo de mudanças trazendo algumas transformações importantes para as 
universidades brasileiras. A criação da Coordenação de Aperfeiçoamento de Pessoal de Nível Superior (Capes) e do Conselho Nacional de Pesquisa (CNPq) passou a estimular o desenvolvimento de pesquisas e começaram a proliferar os programas de pós-graduação. A Universidade do Brasil desde 1946 já havia criado o doutorado na FNFi e introduzido em seu estatuto a denominação de pósgraduação para designar uma nova modalidade para os cursos superiores (FALCON, 2012).

No caso específico da História, novas perspectivas foram abertas com a separação, em 1955, dos cursos de História e de Geografia nas faculdades de filosofia. A instituição de dois cursos distintos propiciou transformações expressivas que permitiram uma maior oxigenação dos cursos de História, na medida em que ampliou e diversificou sua grade disciplinar, com a introdução de novas disciplinas, mas também promoveu uma mudança na identidade do profissional que se licenciava em História.

As transformações da sociedade brasileira nos anos 1950 constituíram fortes condicionantes para estimular mudanças tanto no âmbito da universidade e das licenciaturas, como na educação básica do país.

Em 1958 já havia sido lançada a Campanha pelas Reformas de Base, que incluíam a reforma agrária, a reforma financeira e a reforma educacional. Nesse contexto, o debate no Congresso sobre o projeto da Lei de Diretrizes e Bases da Educação Nacional, em tramitação desde 1948, ganhou maior vulto. Da mesma forma, a Reforma Universitária passou a ser tema central na agenda das forças de esquerda (FERREIRA, 2015).

No tocante à Lei de Diretrizes e Bases da Educação Nacional, deve-se lembrar que o projeto de lei só foi aprovado em 1961, em virtude do intenso debate travado no âmbito do Estado e da sociedade civil entre os que defendiam a prioridade da escola pública e os partidários da liberdade de ensino. Para os primeiros, os recursos do Estado deveriam ser empregados na manutenção e na expansão das escolas oficiais, que teriam a obrigação de ministrar um ensino gratuito e laico. Para os outros, esses recursos deveriam ser destinados às instituições particulares, que ministrariam o ensino conforme as orientações ideológicas das famílias, cabendo ao Estado apenas 
ocupar o espaço não preenchido pela iniciativa privada. Nesse debate envolveram-se associações profissionais, entidades culturais, sindicatos, entidades estudantis, organizações religiosas e imprensa. A despeito das disputas, a LDB representou um passo importante para a reformulação do ensino superior, visando à expansão da pesquisa científica e estimulando a criação de cursos de mestrado e doutorado em diferentes universidades.

No que diz respeito à Reforma Universitária, o foco da discussão era a política universitária altamente centralizada estabelecida a partir de 1937 pelo Ministério da Educação (BOMENY, 1994). No início dos anos 1960, os debates relativos à universidade transbordaram os limites do meio acadêmico e passaram a mobilizar outros setores sociais. Da agenda de discussões faziam parte temas como o aumento do número de vagas, ou seja, a democratização do ensino superior; a ampliação e a expansão dos cursos; a diversificação das funções do ensino universitário, para destacar os temas mais importantes.

Essas discussões envolviam diferentes segmentos da sociedade brasileira, em especial os estudantes universitários, que tinham como órgão máximo de representação a União Nacional dos Estudantes (UNE). A Reforma Universitária foi debatida em seminários promovidos pela UNE entre 1961 e 1963, sendo destacado o combate à estrutura arcaica do ensino superior, à privatização e à seletividade econômica dos exames vestibulares, bem como a defesa do aumento da participação da entidade no processo decisório das instituições de ensino.

A conjuntura que se inaugurou no país no final dos anos 1950 foi marcada por um processo de radicalização dos movimentos sociais e pela polarização entre direita e esquerda. Delineava-se um contexto político de combate ao comunismo e à Revolução Cubana. Por outro lado, a crescente mobilização dos trabalhadores, tanto nas cidades quanto no campo, reivindicando não só melhorias salariais, como também mudanças na estrutura desigual da sociedade, oferecia estímulos para que os estudantes universitários se engajassem de forma mais efetiva nas lutas sociais.

O movimento pelas reformas, ainda que incorporando diferentes tendências sociais, defendia a ideia de que a educação exigia uma reformulação dos objetivos e uma reestruturação pedagógica para 
se ajustar ao processo histórico do país. A universidade, segundo os defensores da reforma, deixava de acompanhar as mudanças sociais, e não mais conseguia ser responsável pela pesquisa científica e pelo desenvolvimento tecnológico.

No campo especifico da História os debates se intensificaram especialmente com a criação da Associação Nacional de História (ANPUH), em 1961. Uma temática recorrente era a defesa do estudo da História recente, em oposição aos cursos que se voltavam essencialmente para o conhecimento do passado. Preocupados com as questões sociais do presente e comprometidos com a necessidade de compreensão do mundo contemporâneo a partir de uma perspectiva brasileira, os defensores da nova postura profissional afirmavam que a História deveria se envolver com os problemas da atualidade, e o conhecimento histórico deveria apresentar explicações e possíveis soluções (PEREIRA, 1998). Para que o ensino de História pudesse ser revisto, a formação do profissional deveria também ser modificada. Os livros didáticos teriam que dar maior atenção ao estudo da História recente do Brasil.

A temática da necessidade de transformações no ensino da História se manifestou em diversas ocasiões e através de diferentes canais. No I Congresso Brasileiro de Universitários de História, em 1960, as questões debatidas foram as problemáticas do ensino da História, a formação profissional do professor e as deficiências do livro didático no ensino secundário. Os estudantes dos Centros de Estudos de História da FNFi, da Faculdade de Ciências e Letras (FFCL) da Universidade de Minas Gerais (UMG) e da FFCL da Universidade de São Paulo (USP) assumiram uma postura crítica em relação aos cursos de História de suas faculdades.

As discussões travadas no congresso, focadas tanto na necessidade de renovação do ensino universitário através das licenciaturas, como no ensino da História na educação básica, aguçaram as críticas feitas aos cursos das faculdades, aos catedráticos e à estrutura universitária (PEREIRA, 1998, p. 38). Se os estudantes travavam intensos debates acerca da realidade brasileira e da necessidade urgente de modificar o perfil do curso de História com vistas à formação de professores e à renovação do ensino da História na educação básica, os professores também estavam mobilizados nessa direção. 
É nesse contexto de intensas discussões sobre a realidade brasileira e a necessidade de mudanças na universidade em geral, e no ensino da História em particular, que ganha destaque a realização, em Marília, em 1961, do I Simpósio dos Professores de História do Ensino Superior, e em especial a participação no encontro dos professores de História da Universidade do Brasil (FALCON, 1963b, p. 187).

Além dos debates especialmente voltados para a pesquisa acadêmica, o simpósio discutiu vários aspectos políticos relativos ao perfil do curso de História e de seus professores. Foram votadas moções e resoluções, tais como: a revisão do currículo do curso de História; a constituição de um grupo de trabalho para o planejamento da revisão terminológica da ciência histórica; o intercâmbio cultural entre os cursos de História das diversas faculdades do país, e a revogação da portaria que permitia o registro em História aos licenciados em Pedagogia, Filosofia e Ciências Sociais (FALCON, 1963b, p. 202).

Se professores e alunos debatiam intensamente o ensino da História, as necessidades de mudanças nas licenciaturas e na formação de professores, bem como na produção de material didático, os órgãos governamentais tampouco estavam ausentes da discussão. A Campanha de Assistência aos Alunos (CASES) apresentava-se como um caminho interessante para contornar esses problemas, e demonstrava com clareza o empenho do Ministério da Educação em estimular tanto a produção como a distribuição de material didático.

No caso específico da História, debates importantes foram travados, e prevalecia a visão de que os programas do nível médio tinham se formado de cima para baixo, em consonância com uma concepção em que o presente não era o campo de estudo da História. As propostas apresentadas visavam exatamente a uma renovação da mentalidade dos docentes, através de sugestões voltadas para a "amplitude e desenvolvimento" dos programas de História de nível médio. Os pontos fundamentais defendidos eram privilegiar o estudo da História Contemporânea (séculos XIX e XX), realçando a posição e os problemas do Brasil e da América, assim como dos povos em processo de desenvolvimento, e apresentar temas da História Antiga e Medieval a partir das contribuições dessas etapas 
do desenvolvimento social para nossa civilização. Segundo Ferreira (2015, p. 154-155), o argumento central era que "[...] os fatos históricos precisam ser estudados pelo que representam para o mundo atual, pois se trata de ajustar o educando à vida [...] para formar seres atuantes, de espírito democrático". Os inovadores refutavam também a afirmação de que o "[...] presente é complexo e, por isso, deve-se ficar no estudo do passado, [...] pois esse, por sua vez também complexo, isolado da vida objetiva do aluno, é de análise mais difícil". No entender dos professores participantes dos seminários por outro lado, "[...] partir da análise do presente, buscar sua lógica no passado, e a ele retornar, é perfeitamente possível”.

Essas propostas de inovação, que tinham como meta melhor preparar os docentes para atuar no ensino básico, eram reflexos dos debates acerca da educação e do seu papel na luta contra o subdesenvolvimento e na conscientização da população e encontravam eco nas universidades e nos centros de estudos de história.

Do exposto pode-se perceber os debates e os embates travados nos anos 1950-1960 no campo do ensino da História. Partindo de diferentes instâncias, os professores, os alunos dos centros de estudos históricos, os professores secundários, a então recém-criada ANPUH, o Conselho Federal de Educação, todos defendiam que os objetivos, os conteúdos e os métodos do ensino da História deveriam mudar.

\section{A Reforma Universitária de 1968 e a expansão dos programas de Pós-Graduação}

Todo esse processo de discussão e de proposta de mudança em curso durante o governo Goulart foi interrompido com o golpe militar de 1964. A instalação do novo regime político recolocaria na ordem do dia a Reforma Universitária, mas agora sob a égide de um governo autoritário. Entre 1964 e 1968 foram encaminhadas as principais questões referentes ao ensino superior tais como o modelo de universidade, a natureza e estrutura dos cursos de pós-graduação, e o controle político-ideológico sobre os corpos docentes e discentes (FALCON, 2012). Já em agosto de 1965 foi 
aprovado o Parecer n⿳ 977/65, de autoria de Newton Sucupira, que definiu o que deveria ser a pós-graduação, fixando-lhe a natureza e objetivos e impondo um modelo único, o que contrariava as alternativas debatidas no pré-641.

$\mathrm{Na}$ área de História seria exatamente ao longo dos anos 70 que surgiriam os primeiros cursos de mestrado de acordo com as novas diretrizes. Em 1970, no Instituto de Filosofia e Ciências Sociais da Universidade do Federal do Rio de Janeiro (IFCS-UFRJ), foi criado um Curso de Extensão e Aperfeiçoamento em História, regulamentado pelo Conselho de Ensino para Graduados (CEPG) da UFRJ, referido por alguns como Curso de Mestrado - na prática, este só seria regulamentado em 1982.

Nos anos subsequentes foram sendo criados vários outros cursos. Em 1971, foi criado o curso de Mestrado em História da USP e da Universidade Federal Fluminense (UFF). Em 1973 surgiam os cursos da PUC do Rio Grande do Sul e da Universidade Federal do Paraná (UFPR). Em 1974 o da Universidade Federal de Pernambuco, em 1975 o da Universidade Federal de Santa Catarina e da Unicamp, em 1976 o da UnB e em 1979 o da UNESP. A USP já possuía sua Pós-Graduação em História, mas nos anos 70 este passaria por modificações para se adequar à regulamentação federal.

Esses primeiros cursos criados no começo dos anos 70, ainda que trouxessem inovações articulando o ensino e a pesquisa, estavam fortemente marcados por um caráter autoritário, imposto pela Reforma Universitária e pelo processo da "institucionalização da pós-graduação”. Na opinião de Francisco Falcon,

Os primeiros cursos de mestrado em História transplantaram para o nível de pós-graduação as mesmas segmentações disciplinares existentes na graduação, quando não transferiram também, é oportuno lembrar, muitas das tradições acadêmicas vinculadas às cátedras e a supremacia dos cursos sobre a pesquisa (FALCON, 1999-2000, p. 134).

No seu entender, a quantidade exagerada de créditos, um grande número de disciplinas a serem cursadas, a crença na necessidade de preenchimento das lacunas da graduação e o lugar secundário reservado à pesquisa dificultavam que novos programas de 
pós pudessem preparar de fato produtores de novos conhecimentos. Além disso o corpo docente dos novos programas constituiu-se, no todo ou em parte, com docentes (titulados) dos cursos de graduação e, talvez mais importante, coube aos departamentos tomar as decisões acadêmicas relativas à estrutura e funcionamento dos futuros cursos de mestrado (FALCON, 1999-2000). Vários anos se passariam até que o mestrado deixasse de ser uma revisão e aprofundamento da graduação para realmente focalizar a formação do pesquisador.

A partir do final da década de 1970, as fragilidades e limitações levaram muitos programas a rever as linhas de pesquisas e buscar uma maior conexão com as pesquisas efetivas de docentes e discentes. No entanto, muitas dificuldades ainda persistiam, pois as atividades de pesquisa e as ofertas de cursos em nível de pós-graduação estavam longe de alcançar um nível desejável (FALCON, 1999-2000).

Ainda assim, Rodrigo Patto Sá Motta (2014) interpreta a Reforma Universitária como um projeto de "modernização autoritário-conservadora”, caracterizado pela racionalização dos recursos e alterações na graduação, como o formato do ingresso, e reconhece que houve uma significativa ampliação do fomento à pós-graduação e uma expansão do sistema universitário no seu todo. De acordo com os números por ele apresentados, em 1964 havia 23 cursos de pós-graduação no Brasil, enquanto em 1974 eles passaram a 400; o número de estudantes universitários subiu de $140 \mathrm{mil} \mathrm{em}$ 1964 para 1 milhão e 300 mil em 1979; as bolsas de pós-graduação financiadas pelas agências federais (Capes e CNPq) passaram de aproximadamente mil em 1964 para cerca de 10 mil em 1976 (MOTTA, 2014, p. 15).

Complementando essa avaliação, Manuel Domingos (2004) declara que foi na ditadura que o CNPq e a Capes se firmaram enquanto instituições de apoio ao desenvolvimento científico. $\mathrm{O}$ trabalho de Carine Muguet (2016), com um foco específico na área de História, avança no acompanhamento dessa trajetória ao chamar atenção para a expansão da pós-graduação na década de 1980, que conferiu ao ensino superior um formato diferente do adotado nas décadas anteriores, com o ensino sistemático voltado para a capacitação profissional e o desenvolvimento científico.

De acordo com os dados da Capes, podemos perceber a grande expansão do ensino de pós-graduação, com o aumento não 
só do número de cursos de mestrado e também de doutorado, mas do número de alunos bolsistas. Os quadros abaixo, com dados a partir de 1998, comprovam essa avaliação.

\section{Quadro 1 - Distribuição de Programas de Pós-Graduação} em História no Brasil, segundo dados da Capes

\begin{tabular}{|l|c|c|c|c|}
\hline & $\begin{array}{c}\text { Mestrado/ } \\
\text { Doutorado }\end{array}$ & Mestrado & $\begin{array}{c}\text { Mestrado } \\
\text { Prof. }\end{array}$ & Total \\
\hline $\mathbf{1 9 9 8}$ & 15 & 4 & 0 & 19 \\
\hline $\mathbf{1 9 9 9}$ & 15 & 10 & 0 & 25 \\
\hline $\mathbf{2 0 0 0}$ & 15 & 11 & 0 & 26 \\
\hline $\mathbf{2 0 0 1}$ & 19 & 9 & 0 & 28 \\
\hline $\mathbf{2 0 0 2}$ & 19 & 9 & 0 & 28 \\
\hline $\mathbf{2 0 0 3}$ & 19 & 9 & 1 & 29 \\
\hline $\mathbf{2 0 0 4}$ & 21 & 11 & 1 & 33 \\
\hline $\mathbf{2 0 0 5}$ & 21 & 13 & 1 & 35 \\
\hline $\mathbf{2 0 0 6}$ & 22 & 19 & 1 & 42 \\
\hline $\mathbf{2 0 0 7}$ & 23 & 27 & 1 & 51 \\
\hline $\mathbf{2 0 0 8}$ & 24 & 28 & 1 & 53 \\
\hline $\mathbf{2 0 0 9}$ & 24 & 28 & 1 & 53 \\
\hline $\mathbf{2 0 1 0}$ & 25 & 28 & 1 & 54 \\
\hline $\mathbf{2 0 1 1}$ & 30 & 26 & 1 & 57 \\
\hline $\mathbf{2 0 1 2}$ & 30 & 31 & 2 & 63 \\
\hline $\mathbf{2 0 1 3}$ & 38 & 22 & 3 & 63 \\
\hline $\mathbf{2 0 1 4}$ & 38 & 22 & 9 & 69 \\
\hline $\mathbf{2 0 1 5}$ & 39 & 20 & 9 & 68 \\
\hline
\end{tabular}

Fonte: GEOCAPES, 2016. 


\section{Quadro 2 - Concessão de Bolsas de Pós-Graduação da Capes na área de História}

\begin{tabular}{|c|c|}
\hline Ano & $\begin{array}{c}\text { Concessão de Bolsas de Pós-Graduação da Capes no } \\
\text { Brasil - Valores totais } \\
\text { (Área: História) }\end{array}$ \\
\hline $\mathbf{1 9 9 8}$ & 596 \\
\hline $\mathbf{2 0 0 0}$ & 554 \\
\hline $\mathbf{2 0 0 5}$ & 620 \\
\hline $\mathbf{2 0 1 0}$ & 1097 \\
\hline 2014 & 1915 \\
\hline
\end{tabular}

Fonte: GEOCAPES, 2016.

O acompanhamento do processo de institucionalização do ensino universitário e de formação de profissionais de História nos mostra as diferentes conjunturas, os embates, os projetos, as divergências e os esforços que o campo dos estudos históricos atravessou, com a progressiva transformação de seus cursos, de essencialmente formadores de docentes para a educação básica, em direção a um novo perfil com ênfase maior na pesquisa e na pós-graduação (FERREIRA, 2012).

\section{A pesquisa como opção privilegiada}

A despeito das enormes perdas trazidas pelo regime militar, com as cassações e perseguições a alunos e professores, a partir dos anos 70 o crescimento do sistema de pós-graduação foi exponencial. Nesse contexto, começou a se delinear um novo modelo de curso de História, em que a pós-graduação e as atividades de pesquisa passavam lentamente a ocupar um lugar-chave, com investimentos expressivos para estruturar a pós-graduação em detrimento da graduação (FERREIRA, 2012). 
Até 1964, as mudanças, inovações ou permanências do curso estavam direcionadas para a formação de professores da educação básica. No entanto, com a consolidação dos programas de pós-graduação tornou-se crescente a tendência a valorizar a pesquisa em detrimento da docência e mesmo a de alguns professores oferecerem resistência a realizar o trabalho com a graduação. Ao logo do tempo cada vez a atividade de orientação e as possibilidades de articulação entre ensino e pesquisa, mais facilitadas na pós, foram ganhando dimensões e prioridades. Em contrapartida as graduações foram se adaptando aos novos tempos, buscando ampliar as atividades de pesquisa através do desenvolvimento das monografias de final de curso e da introdução das bolsas de iniciação científica. Com essas iniciativas o foco das graduações passou a ser formar pesquisadores para ingressar nos programas de pós e não oferecer ferramentas para a sua atuação como professores, destino maior dos cursos de licenciatura.

O debate sobre o formato ideal para os cursos de licenciatura, sobretudo no que diz respeito à distribuição entre as disciplinas de formação pedagógica e as de conteúdo, não constitui uma novidade. $\mathrm{Na}$ década de 1930, quando foi criado um dos primeiros cursos de formação de professores em História, na UDF, já se discutiam essas questões. Buscava-se um equilíbrio entre as atividades de ensino e pesquisa com o objetivo de preparar professores com uma sólida formação historiográfica e, ao mesmo tempo, com os recursos necessários para o exercício de suas atividades docentes. Essa proposta, no entanto, não teve sucesso. Nas décadas seguintes, os cursos de graduação em História, que ficaram a cargo das Faculdades de Filosofia, Ciências e Letras, tiveram como preocupação básica a formação dos professores apenas como transmissores de conhecimento. Os graduados obtinham os títulos de bacharel e licenciado, mas na prática o destino da grande maioria era o magistério.

A instauração do regime militar alterou significativamente não somente o sistema universitário, mas também a organização do sistema educacional na educação básica, através a legislação aprovada em 1971 (5.692/71). 
O ensino básico, entendido como uma ferramenta para o desenvolvimento econômico e para a manutenção da segurança nacional, foi alvo de uma nova estruturação. Segundo a legislação, a formação do professor era enfocada através do estabelecimento de algumas medidas como o aproveitamento de graduados do ensino superior como docentes das disciplinas de formação profissional; a fixação de padrões de vencimentos relacionados à capacitação do professor; a elaboração de critérios para avaliação. ${ }^{2}$

Naquele contexto, o treinamento de professores caracterizavase pela introdução de elementos técnico-pedagógicos no ensino público, como a massificação de conteúdos através de livros didáticos, técnicas de estudo dirigido, novos contornos curriculares e conteúdos técnico-profissionalizantes. $\mathrm{O}$ objetivo era possibilitar o acesso a habilidades básicas, que consolidariam um contingente de profissionais minimamente capacitados para o ingresso no mercado de trabalho. Nesse sentido, é emblemática a instituição do curso que ficaria conhecido como "licenciatura curta", chamado pela Lei 5.692 de licenciatura de primeiro grau, cuja função era formar professores para lecionar nas séries de $1^{\underline{0}}$ grau (1aa $8^{8}$ séries) (FERREIRA; FRANCO, 2008).

No caso específico do ensino da História, a mudança mais significativa foi a criação de uma nova licenciatura, denominada Estudos Sociais, que reunia os conteúdos de História, Geografia e Organização Social e Política do Brasil. Os resultados dessas iniciativas não poderiam ser mais danosos tanto para os cursos de licenciatura, como para os alunos do ensino básico que se deparavam com currículos inadequados e docentes mal preparados.

Paralelamente a estas transformações no ensino básico, a expansão de programas de pós-graduação explicitava de forma mais clara a oposição entre a formação de professores e a de pesquisadores; entre a licenciatura e o bacharelado. $\mathrm{O}$ ingresso de novas gerações nos programas de pós-graduação nos anos 1970 e, posteriormente, nos quadros das universidades trouxe, sem dúvida, uma melhor qualificação de seus profissionais, cada vez mais voltados para pesquisas inovadoras e para o ensino da pós-graduação. No entanto, 
a priorização da carreira acadêmica e uma excessiva especialização temática dos objetos de investigação colocavam em um plano secundário a formação dos docentes. A preocupação de formar alunos que fossem atuar como professores nos níveis médios e que deveriam receber conhecimentos que permitissem a sua melhor preparação para o magistério ficava cada vez mais desvalorizada. $\mathrm{Na}$ prática, estabelecia-se paulatinamente uma separação radical entre as graduações e as Faculdades de Educação, responsáveis por ministrar os conteúdos pedagógicos.

Essas novas configurações das licenciaturas e do ensino foram, ao longo dos anos 1970, alvo de muitas críticas. Em 1986, foi publicado o Diagnóstico e Avaliação dos Cursos de História no Brasil, documento resultante dos trabalhos de um grupo de consultores convocados pela Secretaria de Educação Superior (SESU-MEC). O documento, elaborado após ampla consulta a diversas instituições, questionava a existência dos Estudos Sociais e recomendava a supressão dos cursos recém-criados em todo o Brasil.

As discussões que se estenderam pela década de 1980 apontavam para a superação das concepções da legislação do regime militar. Nesse sentido, crescia a demanda por uma educação voltada para a formação de cidadãos, o que deveria ser refletido em todos os níveis de ensino e, especialmente, na formação de professores. A aprovação de uma nova Lei de Diretrizes e Bases da Educação Nacional (Lei 9.394/96) em 1996, a partir do projeto apresentado ao Senado por Darcy Ribeiro, foi o auge deste processo de amplo debate social sobre a educação, iniciado principalmente com a redemocratização do país.

A nova LDB atribuiu responsabilidades sobre os diferentes níveis de ensino às três esferas governamentais (federal, estadual, municipal) e trouxe uma preocupação maior com a formação dos professores. Um dos grandes impactos da lei sobre a formação de professores deu-se com a determinação de um mínimo de trezentas horas de duração para a disciplina Prática de Ensino na formação docente, mais uma expressão da relevância atribuída pela lei à experiência em sala de aula. Como resultado, alguns departamentos de história buscaram apropriar-se da responsabilidade sobre esse novo contingente de horas, procurando integrar-se ao processo de 
formação de professores ao invés de delegá-lo somente aos departamentos de educação ${ }^{3}$.

A partir da década de 1990 houve uma crescente introdução de instrumentos de avaliação em todos os níveis de ensino, iniciativa que vem permitindo um diagnóstico mais completo do sistema educacional brasileiro. Mas isto não implica a constituição de consensos no que se refere ao formato das licenciaturas e, consequentemente, ao perfil do professor de história. Ainda permanece nas discussões pós-LDB (1996) a dicotomia entre ensino e pesquisa; mais especificamente falando, entre licenciaturas e bacharelados. A necessidade de superação do dilema entre ensino e pesquisa e a busca da formação de um professor-pesquisador aparece largamente tanto nos documentos governamentais quanto nas propostas curriculares dos cursos e das entidades docentes. ${ }^{4}$

No caso dos cursos de História, o que se verifica é uma constante preocupação com a integração entre as duas formações: a do pesquisador e a do professor. Essa preocupação, contudo, nem sempre se reflete na organização curricular dos diferentes cursos em que, frequentemente, as disciplinas de bacharelado são somadas às disciplinas pedagógicas, oferecidas e geridas pelas faculdades de Educação para compor o currículo da licenciatura.

De uma maneira geral, apesar da profusão de debates e da discussão pedagógica produzida a partir de 1996, na enorme maioria dos cursos de licenciatura em história persiste a valorização do pesquisador em detrimento do professor e a separação entre academia e ensino. Nas universidades de maior prestígio, espaços em que deveríamos encontrar professores qualificados para exercer o magistério, frequentemente nos deparamos com a resistência dos docentes às discussões sobre o ensino da disciplina. Postula-se a necessidade de iniciativas que apontem para a integração entre os dois mundos, que reconheçam a importância de uma real aproximação, porém ainda não se encontraram os caminhos efetivos para tal.

O artigo de Júlia Silveira Matos e Adriana Kivanski de Senna, Mestrado profissional de história e a formação docente para a pesquisa (2013), apresenta um quadro importante das tensões existentes no interior das graduações em História e mesmo dos conflitos entre o bacharelado e a licenciatura, chamando atenção para as 
inconsistências do discurso sobre a união entre ensino e pesquisa, já que os meios de avaliação da atuação docente são definidos em termos de sua produção enquanto pesquisador. Como desdobramento de seus argumentos as autoras criticam a visão em que o docente seria apenas um executor das pesquisas realizadas pelos "Historiadores” bacharéis em História e defendem que a docência é o principal espaço de colocação profissional do Historiador. Assim, sejam bacharéis ou licenciados, ambos acabam por se inserir no mercado de trabalho enquanto docentes. Merecem ser mencionados alguns esforços de criação de linhas de pesquisa em ensino de História no interior de programas de pós-graduação acadêmicos de história que visam a aproximar as atividades de pesquisa e ensino, tais como no Programa de Pós-Graduação da Universidade Federal da Paraíba, no Programa de Pós-Graduação da Universidade Estadual do Rio de Janeiro/São Gonçalo (UERJ), no Programa de Pós-Graduação da Universidade Federal do Estado do Rio de Janeiro (UNIRIO) e no Programa de Pós-Graduação da Universidade Estadual de Londrina (UEL). Ainda que essas iniciativas tenham como temática o ensino de história, os resultados de suas pesquisas não estão focados essencialmente na sua aplicação na sala de aula.

Um último ponto que merece destaque é a má remuneração dos docentes dos ensinos fundamental e médio, o que contribui para afastar ainda mais docência e pesquisa. A carreira de professor implica uma extenuante jornada de trabalho, tornando-se cada vez menos atrativa para os recém-formados nas graduações de História. Não raro, os alunos melhor qualificados direcionam suas carreiras para a pós-graduação, afastando-se completamente da atividade docente. Essa situação é verificável em todas as áreas, mas é especialmente dramática no caso da História, onde há uma oferta de profissionais que permanecem no campo pela impossibilidade de encontrar alternativas mais rentáveis. Um outro aspecto importante que merece destaque são as mudanças nos cursos de licenciatura no que diz respeito à origem social dos alunos, que cada vez mais são oriundos das camadas menos favorecidas da população, o que indica que as camadas médias não se interessam mais pela profissão docente. 


\section{A emergência dos mestrados profissionais}

A experiência com mestrados profissionais, ao iniciar-se o século XXI, já não era uma novidade nas comunidades acadêmicas. Embora fosse alvo de resistência de alguns segmentos universitários, há alguns anos essa modalidade de curso vinha se constituindo em diferentes áreas de conhecimento. De acordo com a descrição da Capes, o objetivo do mestrado profissional

[...] é contribuir com o setor produtivo nacional no sentido de agregar um nível maior de competitividade e produtividade a empresas e organizações. As propostas de cursos novos na modalidade Mestrado Profissional devem apresentar uma estrutura curricular que enfatize a articulação entre conhecimento atualizado, domínio da metodologia pertinente e aplicação orientada para o campo de atuação profissional específico. O trabalho final do curso deve ser sempre vinculado a problemas reais da área de atuação do profissional-aluno e de acordo com a natureza da área e a finalidade do curso. ${ }^{5}$ (CAPES, 2016).

Esse foco na aplicabilidade do conhecimento, na equação entre teoria e prática e na exigência de intervenção e impacto social para os resultados obtidos, se por um lado tornaram os mestrados atraentes, por outro suscitaram muitas resistências.

Tania Fisher, em artigo dedicado ao mestrado profissional, não só rebate as críticas mas defende as vantagens dessa modalidade de curso chamando atenção para os benefícios que ela pode trazer para os mestrados acadêmicos. Defende ainda que a prática é um exercício transformador, e que a construção de mestrados profissionais pode contribuir para flexibilizar e inovar a pós-graduação conferindo maior ressonância social à pesquisa, e trazendo uma reflexão sistemática sobre as práticas além das possibilidades oferecidas ao ensino ancorado na experiência. 
À medida que os mestrados profissionais nas áreas tecnológicas se consolidavam, eles paulatinamente se expandiam para a área de ensino. Marco Antonio Moreira, em seu artigo $O$ mestrado (profissional) em ensino (2004), menciona que a proposta original do "Mestrado em Ensino" data de 2001 e tinha como foco a

[...] preparação profissional na área docente focalizando o ensino, a aprendizagem, o currículo, a avaliação e o sistema escolar, seja pela ação direta em sala de aula, seja pela contribuição na solução de problemas dos sistemas educativos, nos níveis fundamental e médio, e no nível superior na formação de professores das licenciaturas e de disciplinas básicas (MOREIRA, 2004, p. 134).

Avançando na caracterização dos cursos, defende que "[...] o mestrado em ensino deve ser específico para cada área de conhecimento; por exemplo, Ensino de Matemática, Ensino de Ciências" e que "[...] em nenhum instante e de nenhuma forma, estejam separadas a formação profissional a que se dirige e a pesquisa associada ao que ela envolve" (MOREIRA, 2004, p. 134).

Um outro trabalho que reflete sobre o mestrado profissional de ensino é a dissertação de Sandra Chícaro, que defende essa modalidade como algo que valoriza o trabalho docente, dotando o professor de perspectivas de análise que o auxiliam a compreender contextos históricos, sociais, culturais e organizacionais nos quais se dá sua atividade docente. Assim, esse profissional se torna mais capaz de agregar o conhecimento à vivência do aluno.

A preocupação com a formação de professores para atuar em diferentes setores acabou estimulando o desenvolvimento de propostas diferenciadas, com a missão de induzir e fomentar a formação continuada de professores da educação básica. Os diagnósticos sobre a gravidade da situação da educação no país apontavam as deficiências das licenciaturas e colocavam como prioridade a formação docente. Nesse sentido, a própria Capes, em 2007, teve suas funções ampliadas para também se ocupar da educação básica. Entre as várias propostas apresentadas, uma novidade era a criação dos mestrados profissionais em ensino em rede, que ganhou relevância 
como alternativa para dar formação continuada para os professores da educação básica. É nesse contexto que surge o ProfMat (2011), o ProfLetras (2011) e o ProfArtes (2013).

\section{O mestrado profissional na área de História}

As iniciativas de organização dessa modalidade de curso também se fizeram sentir na área de História. $\mathrm{O}$ mestrado profissional já não era uma total novidade. Em 2004, o CPDOC da FGV tinha inaugurado o mestrado profissional em Bens Culturais e Projetos Sociais, mas trazer essa iniciativa para a área de ensino representava um grande desafio, já que muitas resistências se faziam sentir. É verdade que as preocupações com a produção de material didático e formas de implementação de formação continuada para professores já se manifestavam em alguns grupos.

Em maio de 2007, no Fórum dos Coordenadores de Pós-Graduação em História, discutiu-se sobre materiais didáticos para a Educação Básica e, mais especificamente, seu reconhecimento como produção dos professores dos Programas de Pós-Graduação ${ }^{6}$. Na ocasião, havia alguma resistência a que a pós-graduação assumisse a responsabilidade pela Educação Básica, devendo restringir-se à pesquisa científica produzida no seu âmbito. Entretanto, superado o estranhamento inicial, organizou-se um Grupo de Trabalho para estudar o assunto. Em maio do ano seguinte, no âmbito do mesmo Fórum, houve a apresentação da Prof ${ }^{-}$Marieta de Moraes Ferreira de um relatório sobre o mercado de livros didáticos no Brasil e a necessidade de um maior envolvimento da comunidade científica com esse tipo de produção, no sentido de superar os distanciamentos entre o ensino escolar de História e as inovações trazidas pelas pesquisas dos Programas de Pós-Graduação. Fez-se, nesse mesmo ano, o encaminhamento de sugestões à Direção da ANPUH e à Capes, que valorizavam a interação entre Universidade e Escola em diferentes frentes ${ }^{7}$. Nas discussões do Grupo de Trabalho do Fórum de Coordenadores de Pós-Graduação em História, a proposta da formação de um mestrado profissional em Ensino de História já 
era aventada, mas não havia ainda consenso sobre o assunto no âmbito mais geral do próprio Fórum.

Mesmo em meio à resistência, em 2012 floresceram as iniciativas pioneiras do Mestrado Profissional em História da Universidade Federal do Rio Grande e o Mestrado Profissional em Ensino de História: Fontes e Linguagens, da Universidade Federal de Caxias do Sul. Mas o investimento maior da Capes ainda estava por vir, com a proposta do mestrado profissional em rede nacional que visa a ampliar o número de docentes da Educação Básica a serem beneficiados, bem como possibilitar intercâmbios entre universidades interessadas em apoiar este tipo de formação continuada de professores.

\section{O foco na Teoria e na Historiografia}

Nesse contexto, em 2012, estimulados pela própria Capes e pela coordenação da área de história ${ }^{8}$ e pelo o funcionamento dos ProfMat e do ProfLetras, programas em rede nacional, novamente a ideia do mestrado profissional em Ensino de História voltou a florescer. Um primeiro grupo de professores, a partir do Instituto de História da UFRJ, iniciou a discussão incorporando logo a seguir representantes de outras universidades do Rio. O projeto inicial estava sendo concebido para ser apenas uma rede regional, mas as orientações da Capes colocaram como pré-condição para a aprovação de um mestrado em rede a ampliação do seu escopo para um formato de caráter nacional com a incorporação de novos núcleos oriundos de outros estados ${ }^{9}$. Assim, de dezembro de 2012 a março de 2013, um grupo de professores dedicou-se à formatação do projeto. Mas como seria esse mestrado? Seria mais um curso de atualização de conteúdo focado no fornecimento de informações factuais e interpretações relativas a esses eventos e temáticas? A despeito de algumas diferenças, um ponto foi consensual desde o início entre o grupo de professores participantes: o curso deveria ter a teoria da história e a historiografia como foco central. Isso queria dizer que o mais importante era trabalhar com o processo de construção do conhecimento histórico e com a premissa de que 
todas as temáticas abordadas deveriam estar relacionadas com a sua prática na sala de aula.

Partindo dessa perspectiva foram definidos objetivos para a capacitação de docentes em nível de Mestrado Profissional, tais como: qualificar os mestrandos/docentes para desenvolver múltiplas competências comunicativas dos alunos em ambiente on-line e off-line; desenvolver com os mestrandos/docentes estratégias para estimular a capacidade de verificação da fidedignidade das informações históricas, levando em consideração sua origem, o momento e o contexto de sua produção; oferecer subsídios para o reconhecimento do potencial patrimonial dos espaços urbanos e rurais para o ensino de História na Educação Básica; fornecer instrumental para que os mestrandos/docentes possam conduzir o processo de avaliação crítica da realidade em suas múltiplas facetas.

O desdobramento desses objetivos se concretizou na definição das áreas de concentração e das linhas de pesquisa. A descrição da área de concentração em Ensino de História explicita quais são as diretrizes adotadas partindo de uma pergunta. Como o conhecimento histórico pode contribuir para a reflexão sobre a relação entre passado/presente/futuro, permeada pela lembrança, pelo esquecimento e pelas expectativas de indivíduos e grupos, considerando que lembrar e esquecer são aspectos constitutivos da vida em sociedade, das identidades culturais e do pertencimento político? Partindo dessa questão, a Pós-Graduação com ênfase em Ensino de História dirige-se a duas demandas complementares. De um lado, à exigência de reflexão sobre o ensino escolar, considerando seus saberes e práticas, bem como a relação com a disciplina de referência. De outro, à necessidade de compreensão das múltiplas formas de ensinar e aprender História vigentes na sociedade contemporânea, para além da escola, que tensionam continuamente tanto a historiografia profissional como o ensino da disciplina em seus diferentes níveis. Isso porque o movimento atual em direção à memória e a luta por direitos contribuiu para acirrar as disputas sobre a escrita e o ensino da História, diversificando suas formas e promovendo múltiplos usos (e abusos) do passado. Cabe ao profissional da área investigar esse complexo movimento e os variados recursos ao conhecimento 
histórico, de modo a compreender a historicidade das experiências e as muitas possibilidades de escrever e ensinar a História.

No que se refere às linhas de pesquisa três temáticas foram definidas. Saberes Históricos no Espaço Escolar, Linguagens e Narrativas Históricas, Produção e Difusão e Saberes Históricos em Diferentes Espaços de Memória.

Concluído o projeto do Mestrado Profissional em Ensino de História em rede nacional tendo como âncora a UFRJ e reunindo 12 Universidades de diferentes localidades, o resultado foi apresentado à Capes para avaliação e aprovado em agosto de $2013^{10}$.

Tratava-se agora de implementar o curso de forma concreta. Inúmeros eram os desafios, desde a obtenção e gestão de recursos, como fazer o processo seletivo nacional e definir critérios para próprio funcionamento dos núcleos locais. Tudo era novo, os problemas administrativos imensos. Apesar das dificuldades, em junho de 2014 o processo seletivo foi realizado com sucesso e a primeira turma foi iniciada em agosto seguinte com 148 alunos, sendo 128 bolsistas. Isto é, todos aqueles que reuniam as condições para o recebimento de bolsa de mestrado mediante a comprovação do vínculo com o ensino de história na educação básica da rede pública.

Nos dois anos seguintes os desafios só aumentaram, mas foram sendo enfrentados de forma bastante bem-sucedida, e os resultados dessa primeira turma estão sendo apresentados agora com as defesas que estão sendo realizadas com sucesso.

Mas viabilizar o curso para a turma de 2014 era só uma parte das nossas preocupações. Com as dificuldades crescentes que o Brasil passou a enfrentar na esfera econômica e política, a partir de 2015 muitas incertezas se avizinharam para a continuidade dos Profs, em especial para os cursos mais recentes como o ProfHistória. Seria possível lançar um edital para expandir a rede nacionalmente e incorporar novos núcleos? Quais seriam as possibilidades ampliação de vagas para lançar um novo edital nacional de seleção de alunos? Mesmo sem respostas claras para essas questões, em abril de 2015 abrimos o processo seletivo para o ingresso de novas universidades. Foram 43 candidatas e foi possível aprovar 18 proponentes $^{11}$. Em seguida, iniciamos os preparativos para a seleção nacional para o 
ingresso de novos alunos. Dessa segunda vez foram 3.284 candidatos inscritos, 794 aprovados e 405 matriculados.

\section{Quadro 3 - Relação de candidatos}

\begin{tabular}{|c|c|c|c|c|}
\hline Turmas & $\begin{array}{c}\text { Vagas } \\
\text { ofertadas }\end{array}$ & Candidatos & Aprovados & Matriculados \\
\hline $\mathbf{2 0 1 4 - 1 6}$ & 152 & 463 & 371 & 146 \\
\hline $\mathbf{2 0 1 6 - 1 8}$ & 423 & 3.284 & 794 & 405 \\
\hline
\end{tabular}

Neste segundo semestre de 2016, o ProfHistória está iniciando uma nova fase com a titulação dos antigos alunos e com a possibilidade de avaliação dos caminhos percorridos - o que foi conquistado, o que merece correção. Um caminho foi aberto mas muitos desafios estão por vir. De toda forma parece claro que os mestrados profissionais em ensino em rede nacional vieram para ficar, e que o ProfHistória está inserido nesta tendência. Certamente correções deverão ser feitas, estratégias poderão ser aprimoradas, mas o ProfHistória pode trazer contribuições de grande relevância para a educação básica, seja beneficiando pessoalmente os professores, seja propiciando o desenvolvimento de métodos e estratégias de ensino. Pode-se mencionar ainda que a criação dos núcleos do ProfHistória nos institutos ou departamentos de história tem funcionado como um estímulo para seus professores, na medida em que muitos docentes que não tinham intenção de se envolver com a educação básica e com o ensino de história, acabam seduzidos pelo projeto. Se em 2007 esse envolvimento era visto com muitas reservas, na atualidade esse preconceito foi rompido. A prova disso é que dos 29 núcleos integrantes do ProfHistória (27 em funcionamento) 22 tem sua origem nos cursos de História ainda que alguns deles em colaboração com as faculdades de educação. Com isso podemos dizer que o ensino de história passou a ser uma área valorizada pelos historiadores deixando para trás o tempo em que era vista como algo de menor relevância. Assim o ProfHistória pode contribuir para uma revitalização da licenciaturas e para uma maior integração da pós-graduação com a graduação. 
O Mestrado Profissional em Ensino de História em Rede Nacional (ProfHistória) pode, assim, cumprir seu objetivo: proporcionar formação continuada que contribua para a melhoria da qualidade do exercício da docência em História na Educação Básica, visando a dar ao egresso qualificação certificada para o exercício da profissão de professor de História.

\section{HISTORY TEACHING, TEACHER DEVELOPMENT AND POSTGRAD- UATE COURSES}

Abstract: This work presents some reflections about the challenges of teaching development of elementary and high school education. The basic idea is to follow the different moments of these trajectory, beginning with the first courses in the 1930's; the changes bringing the military regime with university reform and development of Postgraduate courses in Brazil; finally we analyse the beginning of professional master courses.

Keywords: Teaching of history. Professional master. History teaching development. Historiography.

\section{Notas}

${ }^{1}$ Logo em seguida, em agosto de 1965, foi sancionada a Lei no 4.759, dispondo que as "Universidades e Escolas Técnicas Federais da União, vinculadas ao MEC, sediadas nas capitais dos Estados, serão qualificadas de federais e terão a denominação do respectivo Estado". No caso do Rio de janeiro e Niterói, as universidades passariam a denominar-se UFRJ e UFF. Finalmente, em 1967, o Decreto-lei no 464 instituía a Reforma Universitária e em 69, o Parecer nํ77/69 fixou normas para o credenciamento dos cursos de pós-graduação, aprovado pelo CFE (FALCON, 2012).

${ }^{2}$ SAVIANI, Demerval. A Nova Lei da Educação: LDB, trajetória, limites e perspectivas. Campinas: Autores Associados, 1997.

${ }^{3}$ Posteriormente, foi homologado um parecer do Conselho Nacional de Educação fixando diretrizes para a formação de professores da educação básica em que a carga horária mínima para a prática como componente curricular foi elevada para um total de 400 horas. Ver Parecer CNE/CP 28/2001, homologado em 17/01/2002 e publicado no Diário Oficial da União em 18/01/2002.

Anos 90, Porto Alegre, v. 23, n. 44, p. 21-49, dez. 2016 
${ }^{4}$ SAVIANI, op. cit.; RICCI, Cláudia Sapag. A formação do professor e o ensino de história. 2003. Tese (Doutorado)-Universidade de São Paulo, São Paulo, 2003. ${ }^{5}$ BRASIL. Coordenação de Aperfeiçoamento de Pessoal de Nível Superior (Capes). Mestrado Profissional: o que é? Fundação Capes, 1 abr. 2014. Disponível em: $\langle$ http://www.capes.gov.br/avaliacao/sobre-a-avaliacao/mestrado-profissional-oque-e>. Acesso em: 8 set. 2016.

${ }^{6}$ Grupo de Trabalho sob a coordenação da Prof. Dra. Marieta de Moraes Ferreira (UFRJ) para discutir como as iniciativas e as produções voltadas para a Educação Básica poderiam ser consideradas nas avaliações dos Programas de Pós-graduação pela CAPES. Nesse grupo, integraram-se os profs. José Rivair Macedo (UFRGS) Surama Conde Sá Pinto (Universidade Severino Sombra), Keila Grimberg (UNIRIO), Regina Maria da Cunha Bustamante (UFRJ), Joana Neves (UFPB) e Cláudia Engler Cury (UFPB).

${ }^{7}$ Frentes tais como: 1) na formação inicial: compromisso da pós-graduação com o desenvolvimento das licenciaturas em diferentes modalidades (presencial, semipresencial e educação à distância); 2) na formação continuada: lato sensu / extensão, voltada para a formação de professores; 3) no impacto da produção do Programa na graduação, produção didática, utilização pública e escolas; 4) no envolvimento dos Programas de Pós-graduação nas políticas públicas educacionais em diferentes níveis; 5) na participação dos docentes dos Programas nas políticas de inserção dos alunos de Ensino Médio na pesquisa universitária (Iniciação Científica Júnior, Jovens Talentos...); 6) na elaboração de livros didáticos avaliados pelos Programas do MEC (PNLD, PNLEM); 7) na elaboração, organização e difusão de livros paradidáticos e outros materiais didáticos em diferentes mídias (CD/DVD/websites...).

${ }^{8}$ Professores Carlos Fico, Claudia Wasserman e Marcelo Magalhães.

${ }^{9}$ A proposta foi inicialmente apresentada pela Prof ${ }^{\mathrm{a}}$ Marieta de Moraes Ferreira (UFRJ) e desenvolvida por docentes vinculados a seis instituições do Rio de Janeiro, a saber: Alexandre Fortes (UFRRJ), Ana Maria Ferreira da Costa Monteiro (UFRJ), Carmen Teresa Gabriel Anhorn (UFRJ), Felipe Magalhães (UFRRJ), Giselle Martins Venâncio (UFF), Helenice Aparecida Bastos Rocha (UERJ), Keila Grinberg (UNIRIO), Luis Reznik (PUC-Rio), Marcelo de Souza Magalhães (UNIRIO), Márcia Chuva (UNIRIO), Márcia de Almeida Gonçalves (UERJ), Mariana Aguiar Ferreira Muaze (UNIRIO), Rebeca Gontijo Teixeira (UFRRJ) e Regina Maria da Cunha Bustamante (UFRJ). Esse grupo inicial foi responsável pela elaboração do Projeto e do Regimento do Programa de Mestrado Profissional de Ensino em História (PROFHISTÓRIA) que, posteriormente, agregou novos colaboradores do Rio de Janeiro e de outras regiões do país. No total, participam docentes vinculados a seis Instituições de Ensino Superior 
da região sudeste do país; cinco da região sul; uma da região nordeste; e uma da região norte.

${ }^{10}$ Universidade Federal do Rio de Janeiro, Universidade do Estado do Rio de Janeiro, Universidade Federal Rural do Rio de Janeiro, Universidade Federal Fluminense, Pontifícia Universidade Católica do Rio de Janeiro, Universidade Federal do Estado do Rio de Janeiro, Universidade Federal de Santa Maria, Universidade Federal do Rio Grande, Universidade do Estado de Santa Catarina, Universidade Federal de Santa Catarina, Universidade Federal do Rio Grande do Sul, Universidade Federal do Tocantins.

${ }^{11}$ Universidade Estadual de Maringá, Universidade Estadual de Mato Grosso do Sul, Universidade Estadual de Ponta Grossa, Universidade Federal de Mato Grosso, Universidade Federal do Pará, Universidade Federal de Pernambuco, Universidade Federal do Paraná, Universidade Federal do Rio Grande do Norte, Universidade Federal de Sergipe, Universidade do Estado da Bahia, Universidade do Estado de Mato Grosso, Universidade Estadual do Paraná, Universidade Estadual de Campinas, Universidade Federal do Amapá, Universidade Federal de São Paulo, Universidade Regional do Cariri, Universidade Federal de Minas Gerais, Universidade de São Paulo.

\section{Referências}

BELTRÃO, Kaizô. Perfil do historiador graduado. Documento de Trabalho. Rio de Janeiro: FGV, 2016.

BOMENY, Helena. A reforma universitária de 1968: 25 anos depois. Revista Brasileira de Ciências Sociais, São Paulo, v. 26, n. 9, p. 51-65, 1994. Disponível em: 〈www.anpocs.org.br/portal/publicações/rbcs_00_26/rbcs26_04.htm〉. Acesso em: 5 jun. 2011.

BRASIL. Coordenação de Aperfeiçoamento de Pessoal de Nível Superior (Capes). Mestrado Profissional: o que é? Fundação Capes, 1 abr. 2014. Disponível em: <http://www.capes.gov.br/avaliacao/sobre-a-avaliacao/mestrado-profissional-oque-e>. Acesso em: 8 set. 2016.

. Parecer CNE/CES 1363/2001, aprovado em 12 de dezembro de 2001. Retificação do Parecer CNE/CES 492/2001, que trata da aprovação das Diretrizes Curriculares Nacionais dos Cursos de Filosofia, História, Geografia, Serviço Social, Comunicação Social, Ciências Sociais, Letras, Biblioteconomia, Arquivologia e Museologia. Diário Oficial da União, Brasília, DF, 29 jan. 2002. Seção 1, p. 60.

Anos 90, Porto Alegre, v. 23, n. 44, p. 21-49, dez. 2016 
BRASIL. Parecer CNE/CES 492/2001, aprovado em 3 de abril de 2001. Diretrizes Curriculares Nacionais dos cursos de Filosofia, História, Geografia, Serviço Social, Comunicação Social, Ciências Sociais, Letras, Biblioteconomia, Arquivologia e Museologia. Diário Oficial da União, Brasília, DF, 9 jul. 2002. Seção 1, p. 50.

. Resolução CNE/CES 13/2002, de 13 de março de 2002. Estabelece as Diretrizes Curriculares para os cursos de História. Diário Oficial da União, Brasília, DF, 9 abr. 2002. Seção 1, p. 33.

. Parecer CNE/CP 009/2001, aprovado em 8 de maio de 2001. Diretrizes Curriculares Nacionais para a Formação de Professores da Educação Básica, em nível superior, curso de licenciatura, de graduação plena. Diário Oficial da União, Brasília, DF, 18 ago. 2002. Seção 1, p. 31.

. Parecer CNE/CP 28/2001, aprovado em 2 de outubro de 2001. Dá nova redação ao Parecer CNE/CP 21/2001, que estabelece a duração e a carga horária dos cursos de Formação de Professores da Educação Básica, em nível superior, curso de licenciatura, de graduação plena. Diário Oficial da União, Brasília, DF, 18 ago. 2002. Seção 1, p. 31.

. Programa de Mestrado Profissional em Ensino de História (ProfHistória). Fundação Capes, 22 nov. 2010. Disponível em: <http://capes.gov.br/ educacao-a-distancia/prof historia>. Acesso em: 8 set. 2016.

CHÍCARO, Sandra Conceição Ribeiro. Formação pedagógica do enfermeiro professor para o ensino superior. 2015. Dissertação (Mestrado)-Universidade Federal Fluminense, Niterói, 2015.

I CONGRESSO de Professores do Ensino Médio. Boletim de História, Rio de Janeiro, ano 3, n. 6, p. 195-197, jan./jun. 1961.

CONSELHO Federal de Educação. Didática da História. Boletim de História, Rio de Janeiro, v. 5, n. 7, p. 151-155, ago. 1963.

COSTA, Arthur Nogueira Santos e. Ensino de história e currículo: entrevista com Cláudia Spag Ricci. História e Perspectivas, Uberlândia, v. 29, n. 54, p. 283-294, jan./jun. 2016.

DOMINGOS, Manuel. A trajetória do CNPq. Revista Acervo, Rio de Janeiro, v. 17, n. 2, p. 19-40, jul./dez. 2004.

FALCON, Francisco José Calazans. O Programa de Pós-graduação em História Social do IFCS/UFRJ: um ensaio de história e memória. Topoi, Rio de Janeiro, v. 13, n. 25, p. 6-24, jul./dez. 2012.

. A pós-graduação como objeto histórico. Revista Maracanan, Rio de Janeiro, ano I, p. 118-133, 1999-2000. 
FALCON, Francisco José Calazans. O I Simpósio dos Professores de História do Ensino Superior. Boletim de História, Centro de Estudos de História, Faculdade Nacional de Filosofia, Universidade do Brasil, Rio de Janeiro, v. 5, n. 7, p. 187-196, ago. 1963a.

. O II Simpósio dos Professores Universitários de História. Boletim de História, Centro de Estudos de História, Faculdade Nacional de Filosofia, Universidade do Brasil, Rio de Janeiro, v. 5, n. 7, p. 197-203, ago. 1963b.

FERREIRA, Marieta de Moraes. A História como ofício: a constituição de um campo disciplinar. Rio de Janeiro: FGV, 2013.

. Por um novo ensino de história: os desafios dos anos 1950-1960. In: ROCHA, Helenice; MAGALHÃES, Marcelo; GONTIJO, Rebeca (Org.). $O$ ensino de história em questão: cultura histórica, usos do passado. Rio de Janeiro: FGV, 2015.

. Relendo memórias. Topoi, Rio de Janeiro, v. 13, n. 25, p. 6-24, jul./dez. 2012.

FERREIRA, Marieta de Moraes; FRANCO, Renato. Desafios do Ensino de História. Estudos Históricos, Rio de Janeiro, v. 21, n. 41, p. 79-93, jan./jun. 2008.

FERREIRA, Marieta de Moraes; MOREIRA, Regina da Luz (Org.). Capes, 50 anos: Depoimentos ao CPDOC/FGV. Brasília, DF: CAPES, 2002.

FISCHER, T. Mestrado profissional como prática acadêmica. Revista Brasileira de Pós-Graduação, Brasília, DF, v. 2, n. 4, p. 24-29, 2005.

MATOS, Júlia Silveira; SENNA, Adriana Kivanski. Mestrado profissional de história e a formação docente para a pesquisa. Revista Latino-Americana de História, São Leopoldo, v. 2, n. 6, p. 210-222, ago. 2013. Edição especial.

MONTEIRO, Ana Maria. Professores de História: entre saberes e práticas. Rio de Janeiro: Mauad X, 2007.

MOREIRA, Marco Antonio. O mestrado (profissional) em ensino. Revista Brasileira de Pós-Graduação, Brasília, DF, v. 1, n. 1, p. 131-142, jul. 2004.

MOTTA, Rodrigo Patto Sá. A modernização autoritário-conservadora nas universidades e a influência da cultura política. In: REIS FILHO, D. A.; RIDENTI, M.; MOTTA, R. P. S. (Org.). A ditadura que mudou o Brasil: 50 anos do golpe de 1964. Rio de Janeiro: Zahar, 2014a. p. 48-65.

MOTTA, Rodrigo Patto Sá. As universidades e o regime militar: cultura política brasileira e modernização autoritária. Rio de Janeiro: Zahar, 2014b. 
MUGUET, Carine Silva. 1964: as efemérides do golpe e a produção historiográfica acadêmica pós-1964 (1994-2014). 2016. Dissertação (Mestrado em História Social)-Universidade Federal do Rio de Janeiro, Rio de Janeiro, 2016.

PEREIRA, Daniel Mesquita. Boletim de História: uma experiência de vanguarda na Faculdade Nacional de Filosofia - 1958/1963. 1998. Dissertação (Mestrado em História)-Pontifícia Universidade Católica do Rio de Janeiro, Rio de Janeiro, 1998.

RESNIK, Luis. Tecendo o amanhã: a História do Brasil no ensino secundário: programas e livros didáticos (1931 a 1945). Dissertação (Mestrado)-Universidade Federal Fluminense, Niterói, 1992.

RICCI, Cláudia Sapag. A formação do professor e o ensino de história. 2003. Tese (Doutorado)-Universidade de São Paulo, São Paulo, 2003.

RODRIGUES, Mara Cristina de Matos. A institucionalização da formação superior em história: o curso de Geografia e História da UPA/URGS - 1943 a 1950. 2002. Dissertação (Mestrado)-Universidade Federal do Rio Grande do Sul, Porto Alegre, 2002.

ROUSSO, Henry. La dernière catastrophe: l'histoire, le présent, le contemporain. Paris: Gallimard, 2013.

SAVIANI, Demerval. A Nova Lei da Educação: LDB, trajetória, limites e perspectivas. Campinas: Autores Associados, 1997.

UM POUCO de luz sobre a educação no Brasil e suas causas. Boletim de História, Rio de Janeiro, v. 1, n. 2-3, p. 133-145, jan./mar-abr./jun. 1959.

UNIVERSIDADE FEDERAL DO RIO DE JANEIRO. Instituto de História. Pós-Graduação - ProfHistória. Instituto de História UFRJ, [20--]. Disponível em: <http://historia.ufrj.br/posprofhistoria.php〉. Acesso em: 8 set. 2016.

Recebido em: 29/07/2016

Aprovado em: 01/10/2016 